\title{
Conventional 3D conformal radiotherapy and volumetric modulated arc therapy for cervical cancer: Comparison of clinical results with special consideration of the influence of patient- and treatment-related parameters
}

\author{
Leif Hendrik Dröge ${ }^{1}$ - Franziska-Felicitas von Sivers ${ }^{1}$ - Markus Anton Schirmer ${ }^{1}$ Hendrik Andreas Wolff',3,4
}

Received: 9 November 2020 / Accepted: 30 March 2021 / Published online: 3 May 2021

(c) The Author(s) 2021

\begin{abstract}
Purpose Intensity-modulated radiotherapy (IMRT) for cervical cancer yields favorable results in terms of oncological outcomes, acute toxicity, and late toxicity. Limited data are available on clinical results with volumetric modulated arc therapy (VMAT). This study's purpose is to compare outcome and toxicity with VMAT to conventional 3D conformal radiotherapy (3DCRT), giving special consideration to the influence of patient- and treatment-related parameters on side effects.

Materials and methods Patients with cervical cancer stage I-IVA underwent radiotherapy alone or chemoradiotherapy using 3DCRT $(n=75)$ or VMAT $(n=30)$. Survival endpoints were overall survival, progression-free survival, and locoregional control. The National Cancer Institute Common Terminology Criteria for Adverse Events and the Late Effects of Normal Tissues criteria were used for toxicity assessment. Toxicity and patient- and treatment-related parameters were included in a multivariable model.

Results There were no differences in survival rates between treatment groups. VMAT significantly reduced late small bowel toxicity $(\mathrm{OR}=0.10, p=0.03)$. Additionally, VMAT was associated with an increased risk of acute urinary toxicity $(\mathrm{OR}=2.94, p=0.01)$. A low body mass index $(\mathrm{BMI} ; \mathrm{OR}=2.46, p=0.03)$ and overall acute toxicity $\geq$ grade $2(\mathrm{OR}=4.17$, $p<0.01)$ were associated with increased overall late toxicity.

Conclusion We demonstrated significant reduction of late small bowel toxicity with VMAT treatment, an improvement in long-term morbidity is conceivable. VMAT-treated patients experienced acute urinary toxicity more frequently. Further analysis of patient- and treatment-related parameters indicates that the close monitoring of patients with low BMI and of patients who experienced relevant acute toxicity during follow-up care could improve late toxicity profiles.
\end{abstract}

Keywords Gynecologic cancer · Radiochemotherapy · Intensity-modulated radiotherapy · Urinary toxicity · Small bowel toxicity $\cdot$ Body mass index

This work is part of the doctoral thesis of Franziska-Felicitas von Sivers.

Availability of data and material The datasets generated and/or analyzed in the current study are available from the corresponding author by reasonable request.

Dr. Leif Hendrik Dröge, MD

Hendrik.droege@med.uni-goettingen.de

1 Department of Radiotherapy and Radiation Oncology, University Medical Center Göttingen, Robert-Koch-Straße 40, 37075 Göttingen, Germany
University Medical Center Göttingen, Göttingen, Germany

3 Department of Radiology, Nuclear Medicine and Radiotherapy, Radiologie München, 80333 Munich, Germany

4 Department of Radiotherapy and Radiation Oncology, University Medical Center Regensburg, Regensburg, Germany 


\section{Introduction}

Radiotherapy and chemoradiotherapy (RT/CRT) reduce local and distant recurrence and improve survival in cervical cancer [1,2], not seldom at the expense of side effects [3-6]. Recently, intensity-modulated radiotherapy (IMRT) and volumetric modulated arc therapy (VMAT) were introduced into radiation oncology practice [7, 8]. IMRT was demonstrated to achieve favorable results in terms of oncological outcomes and toxicity [9-12]. VMAT, at the planning level, achieved excellent dose distributions [13, 14]. On a clinical level, a few studies have reported favorable toxicity profiles or promising outcomes with VMAT, whereby these studies focused on adjuvant treatment [15], neoadjuvant treatment [16], or treatment in elderly patients [17]. However, comparisons of VMAT with other external beam radiotherapy (EBRT) techniques are still rare [18].

We introduced VMAT to our clinic in 2009. The purpose of the current study was to compare clinical results of 3D conformal radiotherapy (3DCRT) and VMAT when treating cervical cancer. The endpoints were outcome and toxicity. We included patient- and treatment-related parameters with a possible influence on side effects in multivariable analysis.

\section{Patients and methods}

\section{Patients}

We included patients who were treated with RT/CRT for cervical cancer of Fédération Internationale de Gynécologie et d'Obstétrique (FIGO) stages I-IVA. Patients with distant metastases or paraaortic lymph node spread were excluded. The staging procedures were performed according to the respective guidelines $[19,20]$ at our gynecological cancer center or at a hospital selected by the patient. Pa- tients received abdominal ultrasound and chest radiograph or a CT scan of the chest and abdomen. A pelvic MRI scan was performed for local tumor staging. A rectoscopy or cystoscopy was performed in patients with clinical or radiological suspicion of invasion into rectum or bladder. According to local practice, surgical staging was not routinely performed. The treatment strategies (e.g., definitive RT/CRT vs. primary surgery) were discussed and determined on an individual basis in the multidisciplinary tumor board. Owing to the changes in treatment strategies over the study period of approximately two decades and to the retrospective study design, it is difficult to further concretize and generalize the indications. Overall, patients with FIGO stages IIIA-IVA were preferably treated with definitive RT/CRT. The options in patients with FIGO stage IIB were, depending on further clinical factors, primary surgery, definitive RT/CRT, and neoadjuvant RT/CRT. Patients with FIGO stages I-IIA preferably underwent primary surgery. The indication for adjuvant RT/CRT was determined depending on histopathological adverse features. A neoadjuvant RT/CRT for cervical cancer is not routinely used outside of clinical trials. Here, according to local practice at our gynecological cancer center, the indication could be set after particularly intense discussion in the tumor board. Patients were informed in detail about the individual treatment character before informed consent was given.

\section{Radiation therapy and chemotherapy}

EBRT was applied with 6-MeV or $20-\mathrm{MeV}$ linear accelerator photons. The target volumes were defined according to the respective guidelines [21, 22]. The planning target volume was defined by adding a $10-\mathrm{mm}$ margin to the clinical target volume. The International Commission on Radiation Units and Measurements (ICRU) reports provided the basis for plan calculation [23, 24]. In 3DCRT, a four-field box
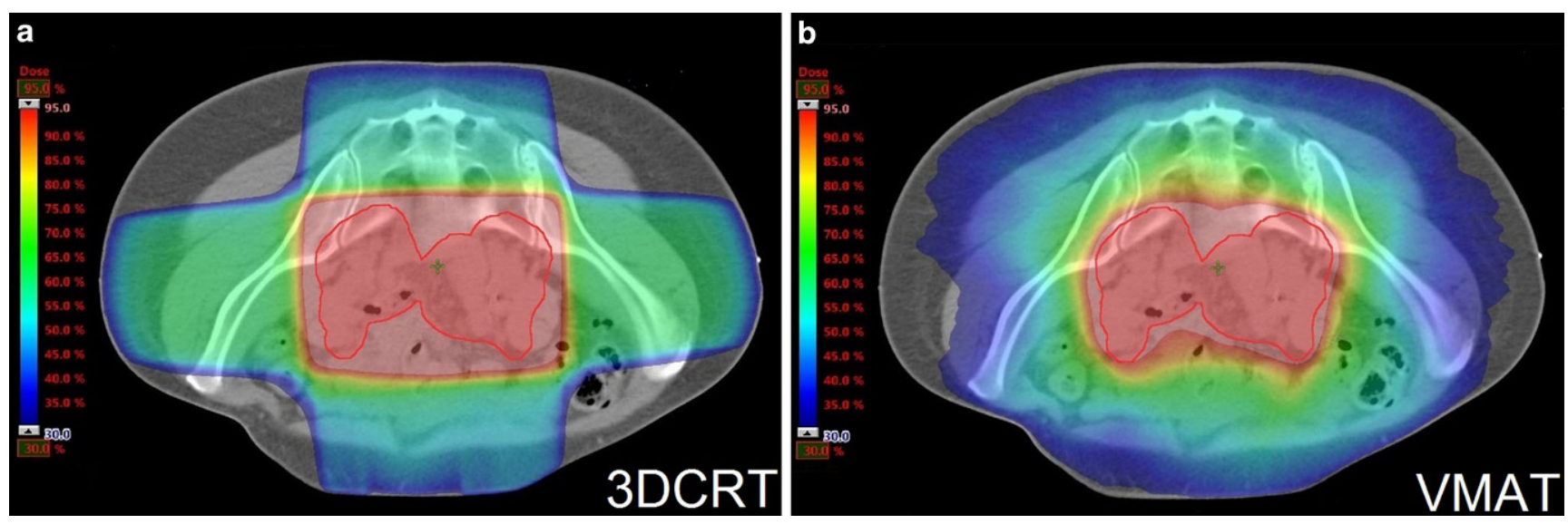

Fig. 1 a,b Intraindividual comparison (transverse views) of dose distributions with a 3D conformal radiotherapy (3DCRT) plan (a) and a volumetric modulated arc therapy (VMAT/RapidArc ${ }^{\circledR}$, Varian Medical Systems, Palo Alto, USA) plan (b). The color wash ranges from $95 \%$ to $30 \%$ of the prescribed dose of $50.4 \mathrm{~Gy}$, the thick red line indicates the planning target volume 
technique (anteroposterior/right and left lateral) was used. In definitive RT/CRT, a two-field technique (anteroposterior/posteroanterior) with central shielding was used for boost therapy [25]. VMAT was performed using RapidArc ${ }^{\circledR}$ (Varian Medical Systems, Palo Alto, USA). The treatment plans were calculated with the progressive resolution algorithm in Eclipse. These dose constraints were used for both 3DCRT and VMAT: small bowel $\geq 50 \mathrm{~Gy}$ in $\leq 10 \mathrm{~cm}^{3}$ volume and $\geq 40 \mathrm{~Gy}$ in $\leq 100 \mathrm{~cm}^{3}$ volume; rectum $\geq 65 \mathrm{~Gy}$ in $\leq 17 \%$ volume and $\geq 40$ Gy in $\leq 50 \%$ volume; bladder $\geq 65$ Gy in $\leq 25 \%$ volume and $\geq 40 \mathrm{~Gy}$ in $\leq 50 \%$ volume. Fig. $1 \mathrm{a}, \mathrm{b}$ and Supplementary Figs. 1a, b and 2 illustrate a comparison of dose distributions and dose-volume histograms with 3DCRT and VMAT.

Where indicated, high-dose-rate brachytherapy was administered. In definitive RT/CRT, in patients with stages IB2-IVA, MRI was performed after EBRT. The treating radiation oncologist chose between an intracavitary or a combined intracavitary/interstitial approach, depending on tumor shrinkage and patient anatomy. The brachytherapy was delivered to a total dose of $24 \mathrm{~Gy}$ (weekly sessions of 6Gy). In postoperative RT/CRT, in patients with close or positive vaginal margins, intracavitary brachytherapy was applied (10 Gy, two sessions of $5 \mathrm{~Gy}$ in 1 week).

Where indicated, chemotherapy was given concurrently with RT. Standardly, weekly cisplatin $\left(40 \mathrm{mg} / \mathrm{m}^{2}\right.$ total body surface area, total $240 \mathrm{mg} / \mathrm{m}^{2}$, six cycles) was administered. In cases of decreased renal function, a different regimen was selected or chemotherapy was omitted.

\section{Assessment of toxicity and follow-up}

The Common Terminology Criteria for Adverse Events (CTCAE) criteria (version 5.0) [26] were used to assess acute toxicities. Patients were monitored at least weekly, including physical examination and the acquisition of blood samples. After RT/CRT, patients were monitored at least every second week until symptoms were satisfactorily controlled. The highest score of skin toxicity, proctitis, enteritis, and urinary toxicity was used to classify the grade of overall acute toxicity. The "Late Effects of Normal Tissues-subjective, objective, management, and analytic" (LENT-SOMA) criteria [27] were used to assess late toxicities. Patients were monitored at least annually for 5 years. The highest score of skin toxicity, proctitis, small bowel toxicity, urinary toxicity and vaginal toxicity was used to classify the grade of overall late toxicity.

\section{Statistics}

The chi-square test (dichotomous variables), the Kendall's tau test (ordinal variables), and the Mann-Whitney U test (continuous variables) were used for univariable compari- son of patient characteristics and toxicity (cut-off $p<0.05$ ). A multivariable model (ordinal logistic regression [28], cutoff $p<0.05$ ) was established in cases of differences in toxicity endpoints in the univariable analysis. First, the variables were dichotomized (see Supplementary Table S1). Secondly, parameters with a tendency towards an influence on toxicity $(p<0.2)$ were included in the multivariable model. The survival times (overall survival, OS; progression-free survival, PFS; and locoregional control, LC) were calculated from the day of RT/CRT initiation. The logrank test was performed to compare treatment groups (cutoff $p<0.05$ ). We used SPSS v12.0 (IBM) for Kendall's tau test, Mann-Whitney U test, and ordinal logistic regression. The chi-square test and the log-rank test were performed using STATISTICA v.10.0.1011.0 (StatSoft Inc.).

\section{Results}

\section{Patients}

In total, 105 consecutive patients (treatment between 11/1995 and 06/2014) met the inclusion criteria. Among these, $75(71 \%)$ were treated with 3DCRT and $30(29 \%)$ with VMAT. During the time period, 8 patients were irradiated with IMRT. Since this study focused on patients treated with VMAT, these patients were not considered in further analysis. Additionally, during the period, in 9 patients, the paraaortic region was included in treatment volumes. Due to the relevant bias for outcomes and toxicities, these patients were excluded from further analysis, too. In the study cohort, the median follow-up was 56.1 months (range 5.0-287.2) for the 3DCRT cohort and 29.3 months (range 5.2-65.3) for the VMAT cohort. Treatment groups were balanced in baseline clinical characteristics (Table 1).

\section{Radiation therapy and chemotherapy}

Definitive RT/CRT was performed in 53 patients $(50 \%)$, adjuvant RT/CRT was performed in 31 patients (30\%), and neoadjuvant RT/CRT was applied in 21 patients (20\%; Table 2). The reasons for omission of brachytherapy were patient refusal $(n=4)$, technical infeasibility $(n=6)$, and deterioration of patient condition $(n=1)$. In total, in $36 / 53(68 \%)$ patients with definitive RT/RCT, in $23 / 31$ patients $(74 \%)$ with adjuvant RT/RCT, and in $21 / 21$ patients (100\%) with neoadjuvant RT/RCT, concomitant chemotherapy was applied. Patients who were not suitable for cisplatin received mitomycin C $(n=4)$, 5-fluorouracil/mitomycin C $(n=1)$, or carboplatin $(n=1)$. 
Table 1 Patient characteristics

\begin{tabular}{|c|c|c|c|}
\hline \multirow[t]{2}{*}{ Parameter } & \multicolumn{2}{|l|}{ Study group } & \multirow[t]{2}{*}{$p$-value } \\
\hline & $\begin{array}{l}\text { 3D conformal } \\
\text { radiotherapy }\end{array}$ & $\begin{array}{l}\text { Volumetric modu- } \\
\text { lated arc therapy }\end{array}$ & \\
\hline$\overline{\text { Age, } \text { years }^{\text {b }}}$ & $55.2(25-88)$ & $56.3(32-87)$ & 0.9 \\
\hline $\begin{array}{l}\text { Body mass } \\
\text { index }\end{array}$ & $25.8(15.7-45.9)$ & $26.7(19.8-40.5)$ & 0.5 \\
\hline \multicolumn{3}{|l|}{ FIGO stage $^{a}$} & 0.1 \\
\hline$I$ & $22(29.4)$ & $7(23.3)$ & \\
\hline II & $25(33.3)$ & $12(40.0)$ & \\
\hline III & $25(33.3)$ & $5(16.7)$ & \\
\hline$I V$ & $3(4.0)$ & $6(20.0)$ & \\
\hline \multicolumn{3}{|c|}{ Histological subtype $^{\mathrm{a}}$} & 0.8 \\
\hline $\begin{array}{l}\text { Squamous } \\
\text { cell }\end{array}$ & $62(82.7)$ & $26(86.7)$ & \\
\hline $\begin{array}{l}\text { Non-squa- } \\
\text { mous cell }\end{array}$ & $13(17.3)$ & $4(13.3)$ & \\
\hline Adenocarcinoma & $11(14.7)$ & $3(10.0)$ & \\
\hline Adenosquamous & $1(1.3)$ & $1(3.3)$ & \\
\hline Undifferentiated & $1(1.3)$ & $0(0.0)$ & \\
\hline \multicolumn{3}{|c|}{ Histologic grading, c } & 0.7 \\
\hline G1 & $2(2.7)$ & $1(3.9)$ & \\
\hline G2 & $56(75.7)$ & $18(69.2)$ & \\
\hline G3 & $16(21.6)$ & $7(26.9)$ & \\
\hline
\end{tabular}

FIGO Fédération Internationale de Gynécologie et d'Obstétrique

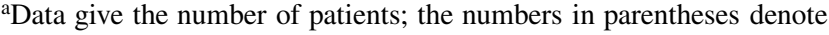
the percentage

${ }^{b}$ Data give the mean, the numbers in parentheses give the range

${ }^{\mathrm{c}}$ The information on histologic grading is missing in five patients

\section{Outcome}

There were no significant differences in outcome between 3DCRT-treated and VMAT-treated patients.

In patients who underwent definitive RT/CRT, the 2-year OS was $61 \%$ for both 3DCRT and VMAT $(p=0.9)$. The 2-year PFS was $80 \%$ for 3DCRT and $74 \%$ for VMAT $(p=0.5)$. The 2 -year LC was $85 \%$ for 3DCRT and $74 \%$ for VMAT $(p=0.6)$.

In patients who received adjuvant RT/CRT, 2-year OS was $96 \%$ for 3DCRT and $100 \%$ for VMAT $(p=0.6)$. The 2-year PFS was $88 \%$ for 3DCRT and $100 \%$ for VMAT $(p=0.5)$. The 2 -year LC was $96 \%$ for 3DCRT and $100 \%$ for VMAT $(p=0.6)$.

In patients who underwent neoadjuvant RT/CRT, the 2-year OS was $82 \%$ for 3DCRT and $90 \%$ for VMAT $(p=0.7)$. The 2 -year PFS was $100 \%$ for 3DCRT and $86 \%$ for VMAT $(p=0.4)$. The 2-year LC was $100 \%$ for both 3DCRT and VMAT $(p=0.3)$.

\section{Toxicity}

Overall acute urinary toxicity occurred more frequently during VMAT treatment, whereas high-grade ( $\geq$ grade 3 ) uri-
Table 2 Treatment characteristics

\begin{tabular}{|c|c|c|}
\hline \multirow[t]{2}{*}{ Parameter } & \multicolumn{2}{|l|}{ Study group } \\
\hline & $\begin{array}{l}\text { 3D conformal } \\
\text { radiotherapy }\end{array}$ & $\begin{array}{l}\text { Volumetric modulated } \\
\text { arc therapy }\end{array}$ \\
\hline \multicolumn{3}{|l|}{ Treatment regimen } \\
\hline Definitive $^{a}$ & $39(52.0)$ & $14(46.7)$ \\
\hline Brachytherapy $^{\mathrm{a}}$ & $32(82.1)$ & $10(71.4)$ \\
\hline $\begin{array}{l}\text { Radiotherapy, total } \\
\text { dose }[G y]^{\mathrm{b}}\end{array}$ & $70.1(59.4-84.4)$ & $69.7(59.0-78.4)$ \\
\hline $\begin{array}{l}\text { Received planned } \\
\text { dose }\end{array}$ & $39(100.0)$ & $14(100.0)$ \\
\hline Postoperative $^{a}$ & $25(33.3)$ & $6(20.0)$ \\
\hline Brachytherapy & $4(16.0)$ & $0(0.0)$ \\
\hline $\begin{array}{l}\text { Radiotherapy, total } \\
\text { dose }[\mathrm{Gy}]^{\mathrm{b}}\end{array}$ & $51.1(48.6-60.4)$ & 50.4 (all patients) \\
\hline $\begin{array}{l}\text { Received planned } \\
\text { dose }\end{array}$ & $24(96.0)$ & $6(100.0)$ \\
\hline Preoperative $^{a}$ & $11(14.7)$ & $10(33.3)$ \\
\hline $\begin{array}{l}\text { Radiotherapy, total } \\
\text { dose }[\mathrm{Gy}]^{\mathrm{b}}\end{array}$ & $46.0(45.0-50.4)$ & $45.5(45.0-50.4)$ \\
\hline $\begin{array}{l}\text { Received planned } \\
\text { dose }\end{array}$ & $11(100.0)$ & $10(100.0)$ \\
\hline \multicolumn{3}{|l|}{ Chemotherapy $^{\mathrm{a}}$} \\
\hline Yes & $56(74.7)$ & $24(80.0)$ \\
\hline Received full dose & $45(80.4)$ & $23(95.8)$ \\
\hline Received cisplatin & $55(98.2)$ & $19(79.2)$ \\
\hline
\end{tabular}

${ }^{\text {a}}$ Data give the number of patients; the numbers in parentheses denote the percentage

${ }^{b}$ Data give the mean, the numbers in parentheses give the range

nary toxicity occurred in only a very small number of patients $(n=1$ for 3DCRT and VMAT, Table 3 [acute organ toxicity] and Supplementary Table S2 [hematologic toxicity]). The late toxicity data were available for 64 3DCRTtreated patients $(85.3 \%)$ and for 26 VMAT-treated patients $(86.7 \%)$. Late small bowel toxicity and overall late toxicity were significantly less frequent in the VMAT group (Table 4).

In multivariable analysis, the VMAT treatment was independently associated with an increased risk of acute urinary toxicity ( $p=0.01$, Table 5 and Supplementary Table S1). In VMAT-treated patients, the risk for late small bowel toxicity was significantly reduced $(p=0.03)$. The overall occurrence of late toxicity was significantly more frequent in patients with low BMI $(p=0.03)$ and in patients with overall acute toxicity $\geq$ grade $2(p<0.01)$.

\section{Discussion}

Within a prospective randomized trial, when comparing IMRT with 3DCRT, Gandhi et al. reported a comparable clinical outcome and a significant reduction of acute and chronic toxicity with IMRT [10]. Thus, high-quality evi- 
Table 3 Acute toxicity

\begin{tabular}{|c|c|c|c|}
\hline \multirow{2}{*}{$\begin{array}{l}\text { Toxicity } \\
\text { grade }\end{array}$} & \multicolumn{2}{|l|}{ Study group } & \multirow[t]{2}{*}{$p$-value } \\
\hline & $\begin{array}{l}\text { 3D conformal } \\
\text { radiotherapy }\end{array}$ & $\begin{array}{l}\text { Volumetric modu- } \\
\text { lated arc therapy }\end{array}$ & \\
\hline \multicolumn{3}{|l|}{$\overline{\text { Skin }^{a}}$} & \multirow[t]{5}{*}{$0.6^{\mathrm{b}}$} \\
\hline 0 & $15(20.0)$ & $4(13.4)$ & \\
\hline 1 & $42(56.0)$ & $19(63.3)$ & \\
\hline 2 & $17(22.7)$ & $6(20.0)$ & \\
\hline 3 & $1(1.3)$ & $1(3.3)$ & \\
\hline \multicolumn{3}{|l|}{ Proctitis $^{a}$} & \multirow[t]{5}{*}{$0.08^{\mathrm{b}}$} \\
\hline 0 & $22(29.4)$ & $3(10.0)$ & \\
\hline 1 & $25(33.3)$ & $13(43.3)$ & \\
\hline 2 & $27(36.0)$ & $13(43.3)$ & \\
\hline 3 & $1(1.3)$ & $1(3.4)$ & \\
\hline \multicolumn{3}{|c|}{ Enteritis $^{a}$} & \multirow[t]{5}{*}{$0.6^{\mathrm{b}}$} \\
\hline 0 & $30(40.0)$ & $12(40.0)$ & \\
\hline 1 & $19(25.4)$ & $5(16.7)$ & \\
\hline 2 & $25(33.3)$ & $12(40.0)$ & \\
\hline 3 & $1(1.3)$ & $1(3.3)$ & \\
\hline \multicolumn{3}{|c|}{ Urinary toxicity $^{a}$} & \multirow[t]{5}{*}{$0.03^{\mathrm{b} *}$} \\
\hline 0 & $45(60.0)$ & $11(36.7)$ & \\
\hline 1 & $24(32.0)$ & $14(46.7)$ & \\
\hline 2 & $5(6.7)$ & $4(13.3)$ & \\
\hline 3 & $1(1.3)$ & $1(3.3)$ & \\
\hline \multicolumn{3}{|c|}{ Overall acute toxicity $^{a}$} & \multirow[t]{5}{*}{$0.18^{\mathrm{b}}$} \\
\hline 0 & $1(1.3)$ & $0(0.0)$ & \\
\hline 1 & $27(36.0)$ & $8(26.7)$ & \\
\hline 2 & $44(58.7)$ & $19(63.3)$ & \\
\hline 3 & $3(4.0)$ & $3(10.0)$ & \\
\hline
\end{tabular}

* Statistically significant $p$-value

${ }^{\text {a }}$ Data give the number of patients; the numbers in parentheses denote the percentage

bUnivariate comparison, Kendall's tau test

dence supports the wide use of IMRT in cervical cancer. Further studies compared planning results with VMAT to results with IMRT $[13,14,29]$. There appears a certain amount of heterogeneity in the results: Cozzi et al. and Sharfo et al. found similar target volume coverage, while Renard-Oldrini et al. found an improvement with VMAT $[13,14,29]$. While Cozzi et al. found improved organs at risk sparing, Sharfo et al. do not support this finding [13, 14]. However, in cervical cancer treatment, VMAT is used only in $26 \%$ of the radiation oncology facilities in Germany [30]. Due to the rareness of the disease, only a limited number of patients are treated per facility [30]. These aspects might explain that to date, only a few, mostly small studies have reported clinical results with VMAT [15-18]. A systematic comparison of VMAT with other EBRT techniques has only been occasionally reported [18]. We herein compared clinical results with VMAT to clinical results with conventional 3DCRT.
Table 4 Late toxicity

\begin{tabular}{|c|c|c|c|}
\hline \multirow{2}{*}{$\begin{array}{l}\text { Toxicity } \\
\text { grade }\end{array}$} & \multicolumn{2}{|l|}{ Study group } & \multirow[t]{2}{*}{$\overline{p \text {-value }}$} \\
\hline & $\begin{array}{l}\text { 3D conformal ra- } \\
\text { diotherapy }\end{array}$ & $\begin{array}{l}\text { Volumetric modulated } \\
\text { arc therapy }\end{array}$ & \\
\hline \multicolumn{3}{|l|}{$\overline{S k i n^{a}}$} & \multirow[t]{4}{*}{$0.9^{\mathrm{b}}$} \\
\hline 0 & $55(85.9)$ & $22(84.6)$ & \\
\hline 1 & $8(12.5)$ & $4(15.4)$ & \\
\hline 2 & $1(1.6)$ & $0(0.0)$ & \\
\hline \multicolumn{3}{|c|}{ Proctitis $^{a}$} & \multirow[t]{6}{*}{$0.5^{\mathrm{b}}$} \\
\hline 0 & $42(65.6)$ & $20(77.0)$ & \\
\hline 1 & $6(9.4)$ & $1(3.8)$ & \\
\hline 2 & $8(12.5)$ & $1(3.8)$ & \\
\hline 3 & $7(10.9)$ & $1(3.8)$ & \\
\hline 4 & $1(1.6)$ & $3(11.6)$ & \\
\hline \multicolumn{3}{|c|}{ Small bowel toxicity ${ }^{a}$} & \multirow[t]{6}{*}{$<0.001^{b}$} \\
\hline 0 & $45(70.2)$ & $25(96.2)$ & \\
\hline 1 & $4(6.3)$ & $0(0.0)$ & \\
\hline 2 & $7(10.9)$ & $0(0.0)$ & \\
\hline 3 & $4(6.3)$ & $1(3.8)$ & \\
\hline 4 & $4(6.3)$ & $0(0.0)$ & \\
\hline \multicolumn{3}{|c|}{ Urinary toxicity $^{a}$} & \multirow[t]{6}{*}{$0.1^{\mathrm{b}}$} \\
\hline 0 & $30(46.9)$ & $18(69.2)$ & \\
\hline 1 & $17(26.6)$ & $3(11.5)$ & \\
\hline 2 & $8(12.5)$ & $3(11.5)$ & \\
\hline 3 & $7(10.9)$ & $0(0.0)$ & \\
\hline 4 & $2(3.1)$ & $2(7.8)$ & \\
\hline \multicolumn{3}{|c|}{ Overall late toxicity $^{a}$} & \multirow[t]{6}{*}{$0.04^{\mathrm{b} *}$} \\
\hline 0 & $19(29.7)$ & $15(57.7)$ & \\
\hline 1 & $15(23.4)$ & $4(15.5)$ & \\
\hline 2 & $12(18.8)$ & $3(11.5)$ & \\
\hline 3 & $12(18.8)$ & $1(3.8)$ & \\
\hline 4 & $6(9.3)$ & $3(11.5)$ & \\
\hline
\end{tabular}

*Statistically significant $p$-value

${ }^{a}$ Data give the number of patients; the numbers in parentheses denote the percentage

bUnivariate comparison, Kendall's tau test

In our study, VMAT significantly reduced late small bowel toxicity. Late small bowel toxicity is known to be correlated with the bowel volume receiving higher radiation doses ( $\geq 50$ Gy) [31]. Cozzi et al. demonstrated a great reduction of the bowel volume receiving $\geq 40$ Gy with VMAT in cervical cancer. This reflects the technique's potential to achieve a minimization of the high-dose volumes [13]. Our study indicates that these dosimetric advantages translate into clinical benefits. In the VMAT group, small bowel toxicity only occurred in 1 patient (3.8\%). Due to the reduction of small bowel toxicity, an improvement in longterm morbidity is absolutely conceivable.

Additionally, it has to be considered that lesser side effects could result in a reduction of treatment breaks, and, consequently, in more effective local and systemic treatment. In our study, there were no differences in sur- 
Table 5 Influence of radiotherapy technique and patient- and treatment-related parameters on toxicity

\begin{tabular}{|c|c|c|c|c|c|c|}
\hline \multirow[t]{3}{*}{ Parameter } & \multirow{2}{*}{\multicolumn{2}{|c|}{$\begin{array}{l}\text { Acute toxicity } \\
\text { Urinary toxicity }\end{array}$}} & \multicolumn{4}{|l|}{ Late toxicity } \\
\hline & & & \multicolumn{2}{|c|}{ Small bowel toxicity } & \multicolumn{2}{|l|}{ Overall late toxicity } \\
\hline & $\mathrm{OR}(\mathrm{CI})$ & $p$-value & $\mathrm{OR}(\mathrm{CI})^{\mathrm{a}}$ & $p$-value & $\mathrm{OR}(\mathrm{CI})$ & $p$-value \\
\hline \multicolumn{2}{|c|}{$\overline{\text { Radiotherapy technique }}{ }^{a}$} & 0.01 & & 0.03 & & 0.1 \\
\hline 3DCRT (75) & 1.00 & - & 1.00 & - & 1.00 & - \\
\hline VMAT (30) & $2.94(1.27-6.67)$ & - & $0.10(0.01-0.78)$ & - & $0.46(0.18-1.16)$ & - \\
\hline \multicolumn{2}{|c|}{ Radiotherapy, total dose $e^{a}$} & 0.4 & & & & \\
\hline$>50.4 \mathrm{~Gy}(65)$ & 1.00 & - & - & - & - & - \\
\hline$\leq 50.4 \mathrm{~Gy}(50)$ & $0.58(0.17-1.93)$ & - & - & - & - & - \\
\hline \multicolumn{2}{|l|}{ Brachytherapy ${ }^{a}$} & 0.5 & & & & \\
\hline Yes (46) & 1.00 & - & - & - & - & - \\
\hline No (59) & $0.67(0.20-2.25)$ & - & - & - & - & - \\
\hline \multicolumn{4}{|c|}{ Hysterectomy prior to treatment ${ }^{a}$} & 0.2 & & \\
\hline Yes (31) & - & - & 1.00 & - & - & - \\
\hline No $(74)$ & - & - & $0.52(0.18-1.51)$ & - & - & - \\
\hline \multicolumn{4}{|c|}{ Acute toxicity, enteritis ${ }^{a}$} & 0.1 & & \\
\hline < grade 2 (66) & - & - & 1.00 & - & - & - \\
\hline$\geq$ grade 2 (39) & - & - & $2.56(0.89-7.69)$ & - & - & - \\
\hline \multicolumn{3}{|c|}{ Body mass index $x^{a, b}$} & & & & $0.03 *$ \\
\hline \multicolumn{7}{|c|}{ Median: 25.4} \\
\hline$\geq$ median (49) & - & - & - & - & 1.00 & - \\
\hline$<$ median (49) & - & - & - & - & $2.46(1.09-5.55)$ & - \\
\hline \multicolumn{3}{|c|}{ Overall acute toxicity ${ }^{a}$} & & & & $<0.01 *$ \\
\hline < grade 2 (36) & - & - & - & - & 1.00 & - \\
\hline$\geq \operatorname{grade} 2(69)$ & - & - & - & - & $4.17(1.69-10.04)$ & - \\
\hline
\end{tabular}

$O R$ odds ratio, $C I$ confidence interval, $3 D C R T 3 \mathrm{D}$ conformal radiotherapy, VMAT volumetric modulated arc therapy

*Statistically significant $p$-value

aParameters were preselected in univariate analysis for multivariate model, see Supplementary Table S1

${ }^{b}$ The information on body mass index is missing in seven patients

vival rates at 2 years. Similarly, previous studies have reported comparable survival rates with IMRT and conventional EBRT techniques [9, 11]. In a study by Roszak et al., gastrointestinal toxicity was the main reason for interruptions of RT/CRT [32], whereas the overall rates of severe gastrointestinal toxicity ( $\geq$ grade 3 ) are lower than $10 \%$ for conventional and novel EBRT techniques $[11,16]$. Similarly, we found $\geq$ grade 3 overall acute toxicity in $\leq 10 \%$ of patients. However, of course, novel EBRT techniques should aim at reducing both severe and less pronounced side effects. Eventually, the already low rates of severe treatment-related toxicity with conventional EBRT techniques might leave limited space to attain improved outcome through a possible reduction of treatment breaks.

Interestingly, we found that the VMAT treatment was associated with an increased risk of acute urinary toxicity. During RT/CRT, genitourinary toxicity is less common than gastrointestinal toxicity, with relevant toxicities in only $1.5 \%$ of patients [4]. These low rates are comparable to $\geq$ grade 3 urinary toxicity with VMAT in our study (3.3\%), with VMAT in the study by Vandecaastele et al. $(0 \%)$, and with IMRT in the study by Gandhi et al. $(0 \%)$
$[10,16]$. Gandhi et al. found no differences in rates of genitourinary toxicity rates when comparing IMRT and conventional 3DCRT [10]. The authors discuss that in their study's 3DCRT-treated patients, the lack of blocks used could have led to higher genitourinary toxicity rates (here, $\geq$ grade 3 toxicity in $13.6 \%$ of the patients) as compared to previous studies [10]. In our study, blocks were used for boost therapy in 3DCRT [25]. Thus, possibly due to the increase in the total volume of the bladder wall being exposed to irradiation with VMAT, higher toxicity rates might be explained. However, the increase was seen primarily in the <grade 3 toxicities. In line with other studies, severe acute urinary toxicity occurred in less than $5 \%$ of all patients $[16$, 17]. Thus, the significance for the whole patient population remains limited and increased attention should be paid to long-term side effects and quality of life, which are especially important from a patient perspective [5]. Finally, due to the relatively small sample size, the heterogeneity of the cohort, and the rare occurrence of genitourinary toxicity, an overinterpretation of the findings should be avoided.

In our study, a low BMI and acute toxicity $\geq$ grade 2 were associated with increased overall late toxicity. Previ- 
ous studies have demonstrated an influence of patient- or treatment-related parameters on side effects in RT/CRT of pelvic malignancies [32-37]. Furthermore, there is evidence that the severity of acute toxicity is correlated with the occurrence of late toxicity [36, 38]. First, we found that a low BMI was associated with a twofold-increased risk of overall late toxicity. In patients treated with CRT, the influence of bodily constitution on chemotherapy pharmacokinetics might explain the differences in damage to normal tissues [35]. Furthermore, the links between adipose tissue, chronic inflammation, and the immune system may provide a possible explanation [34]. Secondly, in our study, overall acute toxicity $\geq$ grade 2 was associated with a fourfold-increased risk of overall late toxicity. This finding is in line with previous studies which found an association of acute toxicity and late toxicity in treatment of gynecologic malignancies [36, 38]. The predictive value of the BMI and of the occurrence of acute toxicity $\geq$ grade 2 bear important implications for clinical practice. In both patient groups, close monitoring during follow-up is reasonable.

A retrospective single-center study may suffer from biases which could have distorted the results. Furthermore, we included patients with different treatment schedules, different radiation doses, different chemotherapy regimens or no concomitant chemotherapy administered, and different staging procedures (e.g., a relevant proportion of patients without surgical lymph node staging). Additionally, we did not include an analysis of dose-volume histograms in our study, which could further clarify the relationships between RT technique and side effects. The multivariable analysis, including patient- and treatment-related parameters, addressed these issues in part. Additionally, the long period of the study might have led to changes in local treatment practice. Since physician-dependent differences in the delineation of target volumes significantly contribute to heterogeneity in RT/CRT of cervical cancer [39], as previously reported, we developed strategies to improve treatment homogeneity [39]. The incidence of cervical cancer is low, and studies on VMAT treatment are rare. Thus, our study significantly contributes to the understanding of the role of VMAT and patient- and treatment-related parameters in $\mathrm{RT} / \mathrm{CRT}$ of cervical cancer.

\section{Conclusion}

We compared VMAT and 3DCRT for cervical cancer. We demonstrated reduced late small bowel toxicity with VMAT. An improvement in long-term morbidity is absolutely conceivable. VMAT-treated patients experienced acute urinary toxicity more frequently. Overall, the rates of high-grade urinary toxicity were very low, limiting the relevance of this finding. During follow-up, the close mon- itoring of patients with a low BMI and of patients who experienced acute toxicity $\geq$ grade 2 could improve late toxicity profiles. Finally, modern irradiation techniques with lower rates of toxicity could pave the way for more effective systemic treatment options. This could result in a relevant improvement of outcomes and quality of life.

Supplementary Information The online version of this article (https:// doi.org/10.1007/s00066-021-01782-5) contains supplementary material, which is available to authorized users.

Funding The authors received no specific financial support for the research, authorship, and/or publication of this article.

Author Contribution LHD, FFS, MAS, and HAW initiated the study. MAS and HAW contributed to its design and coordination. LHD and FFS collected the clinical data. LHD, FFS, MAS, and HAW performed the statistical analysis and interpreted the results. LHD and HAW took the lead in writing the manuscript. All authors read and approved the final manuscript.

Funding Open Access funding enabled and organized by Projekt DEAL.

\section{Declarations}

Conflict of interest L.H. Dröge, F.-F. von Sivers, M.A. Schirmer, and H.A. Wolff declare that they have no competing interests.

Ethical standards This investigation was approved by the local ethics committee of the University of Göttingen Medical Center (application number 8/5/14An). The study has been conducted in accordance with the Declaration of Helsinki principles.

Open Access This article is licensed under a Creative Commons Attribution 4.0 International License, which permits use, sharing, adaptation, distribution and reproduction in any medium or format, as long as you give appropriate credit to the original author(s) and the source, provide a link to the Creative Commons licence, and indicate if changes were made. The images or other third party material in this article are included in the article's Creative Commons licence, unless indicated otherwise in a credit line to the material. If material is not included in the article's Creative Commons licence and your intended use is not permitted by statutory regulation or exceeds the permitted use, you will need to obtain permission directly from the copyright holder. To view a copy of this licence, visit http://creativecommons.org/licenses/by/4. $0 /$.

\section{References}

1. Chemoradiotherapy for Cervical Cancer Meta-Analysis C (2008) Reducing uncertainties about the effects of chemoradiotherapy for cervical cancer: a systematic review and meta-analysis of individual patient data from 18 randomized trials. J Clin Oncol 26:5802-5812

2. Hanna TP, Shafiq J, Delaney GP, Barton MB (2015) The population benefit of radiotherapy for cervical cancer: local control and survival estimates for optimally utilized radiotherapy and chemoradiation. Radiother Oncol 114:389-394

3. Kurrumeli D, Oechsner M, Weidenbacher B et al (2020) An easy way to determine bone mineral density and predict pelvic insufficiency fractures in patients treated with radiotherapy for cervical 
cancer. Strahlenther Onkol. https://doi.org/10.1007/s00066-02001690-0

4. Kirwan JM, Symonds P, Green JA, Tierney J, Collingwood M, Williams CJ (2003) A systematic review of acute and late toxicity of concomitant chemoradiation for cervical cancer. Radiother Oncol 68:217-226

5. Osann K, Hsieh S, Nelson EL et al (2014) Factors associated with poor quality of life among cervical cancer survivors: implications for clinical care and clinical trials. Gynecol Oncol 135:266-272

6. de Boer P, van de Schoot A, Westerveld H et al (2018) Target tailoring and proton beam therapy to reduce small bowel dose in cervical cancer radiotherapy: a comparison of benefits. Strahlenther Onkol 194:255-263

7. Bortfeld T (2006) IMRT: a review and preview. Phys Med Biol 51:R363-R379

8. Otto K (2008) Volumetric modulated arc therapy: IMRT in a single gantry arc. Med Phys 35:310-317

9. Folkert MR, Shih KK, Abu-Rustum NR et al (2013) Postoperative pelvic intensity-modulated radiotherapy and concurrent chemotherapy in intermediate- and high-risk cervical cancer. Gynecol Oncol 128:288-293

10. Gandhi AK, Sharma DN, Rath GK et al (2013) Early clinical outcomes and toxicity of intensity modulated versus conventional pelvic radiation therapy for locally advanced cervix carcinoma: a prospective randomized study. Int $\mathbf{J}$ Radiat Oncol Biol Phys 87:542-548

11. Chen MF, Tseng CJ, Tseng CC, Kuo YC, Yu CY, Chen WC (2007) Clinical outcome in posthysterectomy cervical cancer patients treated with concurrent Cisplatin and intensity-modulated pelvic radiotherapy: comparison with conventional radiotherapy. Int $\mathbf{J}$ Radiat Oncol Biol Phys 67:1438-1444

12. Hasselle MD, Rose BS, Kochanski JD et al (2011) Clinical outcomes of intensity-modulated pelvic radiation therapy for carcinoma of the cervix. Int J Radiat Oncol Biol Phys 80:1436-1445

13. Cozzi L, Dinshaw KA, Shrivastava SK et al (2008) A treatment planning study comparing volumetric arc modulation with RapidArc and fixed field IMRT for cervix uteri radiotherapy. Radiother Oncol 89:180-191

14. Sharfo AW, Voet PW, Breedveld S, Mens JW, Hoogeman MS, Heijmen BJ (2015) Comparison of VMAT and IMRT strategies for cervical cancer patients using automated planning. Radiother Oncol 114:395-401

15. Vandecasteele K, Tummers P, Makar A et al (2012) Postoperative intensity-modulated arc therapy for cervical and endometrial cancer: a prospective report on toxicity. Int J Radiat Oncol Biol Phys 84:408-414

16. Vandecasteele K, Makar A, Van den Broecke R et al (2012) Intensity-modulated arc therapy with cisplatin as neo-adjuvant treatment for primary irresectable cervical cancer. Toxicity, tumour response and outcome. Strahlenther Onkol 188:576-581

17. Chakraborty S, Geetha M, Dessai S, Patil VM (2014) How well do elderly patients with cervical cancer tolerate definitive radiochemotherapy using RapidArc? Results from an institutional audit comparing elderly versus younger patients. ecancer 8:484

18. Lin Y, Ouyang Y, Chen K, Lu Z, Liu Y, Cao X (2019) Clinical outcomes of volumetric modulated arc therapy following Intracavitary/ interstitial Brachytherapy in cervical cancer: a single institution retrospective experience. Front Oncol 9:760

19. AWMF (2014) S3-Leitlinie Diagnostik, Therapie und Nachsorge der Patientin mit Zervixkarzinom. http://www.awmf.org/ uploads/tx_szleitlinien/032-033OLl_S3_Zervixkarzinom_201410.pdf. Accessed: 10 Oct 2020

20. NCCN (2020) Clinical Practice Guidelines in Oncology. http:// www.nccn.org/professionals/physician_gls/pdf/cervical.pdf. Accessed: 15 Oct 2020

21. Lim K, Small W Jr., Portelance L et al (2011) Consensus guidelines for delineation of clinical target volume for intensity-modu- lated pelvic radiotherapy for the definitive treatment of cervix cancer. Int J Radiat Oncol Biol Phys 79:348-355

22. Small W Jr., Mell LK, Anderson P et al (2008) Consensus guidelines for delineation of clinical target volume for intensity-modulated pelvic radiotherapy in postoperative treatment of endometrial and cervical cancer. Int J Radiat Oncol Biol Phys 71:428-434

23. ICRU (1993) Prescribing, recording and reporting photon beam therapy. Report, vol 50. ICRU, Bethesda, USA

24. ICRU (2010) Prescribing, Recording and Reporting IntensityModulated Photon-Beam Therapy (IMRT). Report, vol 83. ICRU, Bethesda, USA

25. Tamaki T, Ohno T, Noda SE, Kato S, Nakano T (2015) Filling the gap in central shielding: three-dimensional analysis of the EQD2 dose in radiotherapy for cervical cancer with the central shielding technique. J Radiat Res 56(5):804-10

26. NIH (2017) Common Terminology Criteria for Adverse Events (CTCAE). https://ctep.cancer.gov/protocoldevelopment/electronic_ applications/docs/CTCAE_v5_Quick_Reference_8.5x11.pdf. Accessed: 15 Oct 2020

27. Rubin P, Constine LS, Fajardo LF, Phillips TL, Wasserman TH (1995) RTOG Late Effects Working Group. Overview. Late Effects of Normal Tissues (LENT) scoring system. Int J Radiat Oncol Biol Phys 31:1041-1042

28. Scott SC, Goldberg MS, Mayo NE (1997) Statistical assessment of ordinal outcomes in comparative studies. J Clin Epidemiol 50:45-55

29. Renard-Oldrini S, Brunaud C, Huger S et al (2012) Dosimetric comparison between the intensity modulated radiotherapy with fixed field and Rapid Arc of cervix cancer. Cancer Radiother 16:209-214

30. Marnitz S, Kohler C, Rauer A et al (2014) Patterns of care in patients with cervical cancer 2012: results of a survey among German radiotherapy departments and out-patient health care centers. Strahlenther Onkol 190:34-40

31. Emami B (2013) Tolerance of normal tissue to therapeutic radiation. Rep Radiother Oncol 1:25-48

32. Roszak A, Warenczak-Florczak Z, Bratos K, Milecki P (2012) Incidence of radiation toxicity in cervical cancer and endometrial cancer patients treated with radiotherapy alone versus adjuvant radiotherapy. Rep Pract Oncol Radiother 17:332-338

33. Sauter M, Lombriser N, Butikofer S et al (2020) Improved treatment outcome and lower skin toxicity with intensity-modulated radiotherapy vs. 3D conventional radiotherapy in anal cancer. Strahlenther Onkol 196:356-367

34. Kizer NT, Thaker PH, Gao F et al (2011) The effects of body mass index on complications and survival outcomes in patients with cervical carcinoma undergoing curative chemoradiation therapy. Cancer 117:948-956

35. Wolff HA, Conradi LC, Schirmer M et al (2011) Gender-specific acute organ toxicity during intensified preoperative radiochemotherapy for rectal cancer. Oncologist 16:621-631

36. Weiss E, Hirnle P, Arnold-Bofinger H, Hess CF, Bamberg M (1999) Therapeutic outcome and relation of acute and late side effects in the adjuvant radiotherapy of endometrial carcinoma stage I and II. Radiother Oncol 53:37-44

37. Corn BW, Lanciano RM, Greven KM et al (1994) Impact of improved irradiation technique, age, and lymph node sampling on the severe complication rate of surgically staged endometrial cancer patients: a multivariate analysis. J Clin Oncol 12:510-515

38. Jereczek-Fossa BA, Jassem J, Badzio A (2002) Relationship between acute and late normal tissue injury after postoperative radiotherapy in endometrial cancer. Int J Radiat Oncol Biol Phys 52:476-482

39. Weiss E, Richter S, Krauss T et al (2003) Conformal radiotherapy planning of cervix carcinoma: differences in the delineation of the clinical target volume. A comparison between gynaecologic and radiation oncologists. Radiother Oncol 67:87-95 